\title{
Store Development Strategies of Mini-box Service Retailers: Analytical Framework and Case Study in Japanese Food Service
}

\author{
Taku Kato $^{1} \&$ Kyoichi Kijima ${ }^{2}$ \\ ${ }^{1}$ Department of Social Sciences, Kyorin University, Tokyo, Japan \\ ${ }^{2}$ Department of Value and Decision Science, Tokyo Institute of Technology, Tokyo, Japan \\ Correspondence: Taku Kato, Department of Social Sciences, Kyorin University, 476 Miyashita-cho, Hachioji-shi, \\ Tokyo 192-8508, Japan. E-mail: takukato@29109.jp
}

Received: May 24, 2012 Accepted: June 19, 2012 Online Published: July 25, 2012

doi:10.5539/ijms.v4n4p1 URL: http://dx.doi.org/10.5539/ijms.v4n4p1

\begin{abstract}
It has been pointed out in the service marketing literature that it is necessary for the growth of the service firms to expand their store network geographically. However, we still do not understand enough how firms should develop store network in the domestic market depending on their growth stage, because relatively little has so far been known regarding both how market expansion is categorized and how market expansion strategies are related to the corporate performance. The purpose of this research is both to classify market expansion strategies of service firms, especially what we would like to call "mini-box service retailers" which develop store networks with hundreds of outlets to cover geographic markets, and to clarify the relationship between their expansion strategies and economic performances by analyzing 52 Japanese food service companies listed in Japan. Main results are (1) market expansion strategies of mini-box service retailers were categorized into five types: Local Concentration, Proactive Expansion, Reactive Expansion, Concentrated National Expansion, Dispersed National Expansion, and (2) both Proactive Expansion and Dispersed National Expansion are found to be more profitable than Local Concentration.
\end{abstract}

Keywords: mini-box service retailer, market expansion, corporate performance, Japanese food service industry

\section{Introduction}

\subsection{Background and Research Objectives: Mini-box Service Retailers}

The subject of this research is the store expansion strategy of what we would like to call "mini-box service retailers", for which few researches have been conducted in service marketing literatures.

Mini-box service retailers sell primary services rather than merchandise at their outlets. Because simultaneous production and consumption is characteristic to those services, mini-box service retailers have to develop as many outlets as possible to increase the coverage rate in the store network. It is hard for them to attract customers from a distant place by making their store size bigger and bigger like big-box retailers because in many cases a trade area of their each outlet is very small. They often open a number of outlets in densely populated area, leading to increase in both customer convenience and market presence of their store brands in the area. Good locations to increase both conveniences for customer and market presence in each area efficiently are determined in advance. They cannot create good locations with their efforts like big-box retailers, so they sometimes parasitically open outlets near or inside of other commercially attractive facilities, e.g., department stores or terminal station. Some of them have national presences, while others focus on local markets. It is not uncommon to find such business with over a thousand branches in one domestic market. Optimizing store locations for them does not mean to open one or two stores each in highly populated markets like big-box retailers, but it means to develop ten or more stores in each market. Site selections are conducted routinely. Sometimes it is a good way to open stores at locations with conspicuous presence in a new geographic market strategically, and sometimes concentrating stores in a certain existing market is necessary for developing sales momentum and deterring competitors' entry to the market. They have to balance those store development activities strategically and the effectiveness of the store expansion strategy should be evaluated by the corporate performance. Branch strategy and management through the store development activities are key determinants of market growth and profit performance for mini-box service retailers. Mini-box service retailers currently seem to 
account for a large and growing part of the retail industry. The variety of mini-box service retailers is wide. There are automobile maintenance and repair stores, automobile rental stores, banks, child-care centers, cram schools, language schools, entertainment parks, fitness centers, health care centers, home maintenance services, hotels, movie theaters, real estate agents, fast-food restaurants, coffee shops, video rental shops and so on.

The purpose of this research is both to classify market expansion strategies of mini-box service retailers in a domestic market and to clarify the relationship between expansion strategies and economic performances. We focused on the food service industry as an example of service fields and 52 Japanese food service companies listed in Japan were analyzed.

\subsection{Significance of this Research}

In this research, we deal with mini-box service retailers' expansion strategies in a domestic market. There have been some studies in the service marketing field around the growth strategy of service firms, but those are not straightly applicable to the business of mini-box service retailers, since those studies tend to be too microscopic or macroscopic. Some studies have indicated benefits brought by building dominance in a market. Classical studies had shown the maximum profitability can be secured by building dominance in a market at the launch stage. Recently Bucklin et al (2008) assessed how changes in the intensity of mature distribution networks might affect consumer choice, in which the subject of research was the automobile industry in the U.S. The relationship between market share and distribution intensity was analyzed, which should help firms evaluate the potential effects of expanding or contracting distribution networks for matured products. Knoben et al (2008) investigated the effects of relocation on a firm's performance, in which the latest geographic position the firm was given. Tolba, A. H (2011) tested the effects of distribution intensity on brand performance such as brand preferences and loyalty, in which empirical tests were conducted in the fuel industry in Egypt. Some study indicates the criteria of choosing a country when a company decides to go global, e.g., Buhner (1987), Elango (2000), Gohshal (1987), Hollensen (2004), Jennet and Hennessey (2001), Kogut, B. (1985a), Kogut, B. (1985b).

However, most of the times, what mini-box service retailers' major concern is how they should grow business constantly and most effectively within the domestic market where they already have a store in presense. That is the area where few studies have seriously been done so far. Regarding research dealing with store expansion of retailers in a domestic market, Laulajainen and Stafford (1987) described how some retailers developed their store networks in one country by mapping the occurrence of fifty American retail chains. Though they also mentioned it was necessary for growth of retailers to establish a strong store network in the local area at their initial growth stage based on some cases of retailers, their literatures did not deal with the relationship between the way of expansion and corporate performance. Simmon and Speck (1988) classified 1073 Canadian retail chain companies in terms of how they expand their store network in Canada.

This research is significant in that it deals both with market expansion of mini-box service retailers in the domestic context as well as the relationship between store development data and corporate performance. Branch strategy and management are key determinants of market growth and profit performance for service retailers (Doyle and Corstjens 1983). It is required to provide managers of the service firms with more straightly applicable studies on the way of market expansion to efficiently cover the domestic market as well as their effects on corporate performances. What should be clarified for mini-box service retailers is that how they should allocate new outlets between dominant formation in existing markets and market expansion to new geographic markets in order to achieve good corporate performances. Our knowledge of dominant strategy to become the most profitable at the initial stage cannot motivate the firms' growth with market expansion. If we could both classify market expansion strategies of mini-box service retailers in domestic market and clarify the relationship between market expansion strategies and their economic performances, it will be shown whether a firm's store expansion behavior always leads the firm to lower profitability or not. The results will give mini-box service retailers some guidelines for planning their market expansion throughout a country.

\section{Theory Development}

\subsection{Classification of Market Expansion Strategies}

Generic strategies for growth and development of service firms and retailers have been mentioned in both service literatures and retailing literatures. Though some authors have shown frameworks showing growth strategy alternatives in service marketing literature, many of them seem to be based on Ansoff's product-market matrix. Kasper et al (2006) applied the Ansoff matrix to services and identified four ways for corporate growth: market penetration, market development, service development and diversification. Lovelock and Wright (1999), Johnson, R (1996) identified them as market focus, service focus, complete concentration and decentralization. 


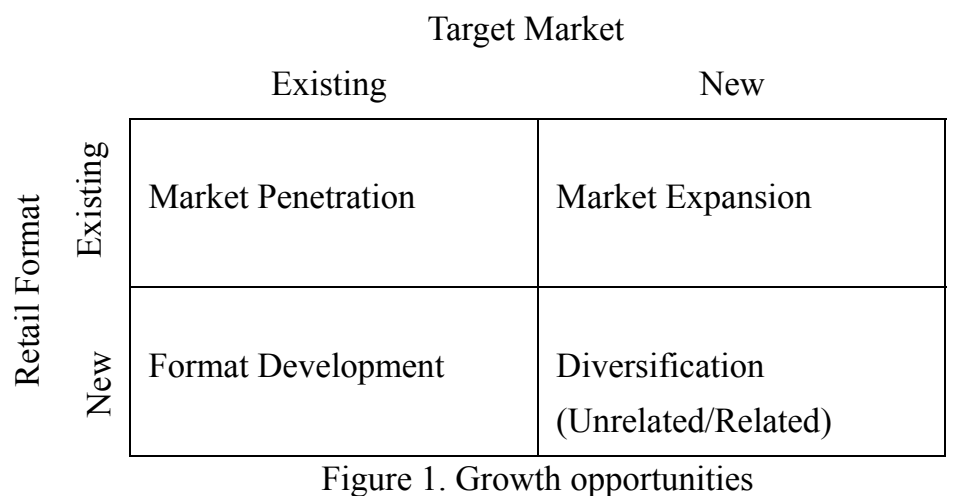

Source: Levy and Weitz (2004) p.160 Exhibit 5-4

Carman and Langeard (1980) identified strategy alternatives for service firms as: market penetration, market expansion, out-of-country expansion, and concentric diversification.

We would like to take the framework of growth opprtunities by Levy and Weitz (2004) as a theoretical base for categorizing growth strategies of mini-box service retailers (Figure 1).

The horizontal axis indicates the synergies between the retailer's present markets and new geographical markets, while the vertical axis indicates the synergies between the retailer's present retail format and the new retail format. Market Penetration at the upper left involves directing efforts toward existing customers by using the present retail format. Format Development at the lower left involves offering a new retail format to the same target market. Market Expansion at the upper right employs the existing retail formats in new market segments by expanding to new geographic markets. Finally, Diversification at the lower right is to introduce a new retail format directed toward a market segment that is currently not served. In this research, we focus only on Market Penetration and Market Expansion among the four strategies and try to elaborate market expansion strategy.

Considering that mini-box service retailers have to progress in market expansion to "new geographic markets" and market share expansion in "existing geographic markets" in parallel, market expansion in this framework seems to be too rough to explain their expansion strategies and therefore it needs to be elaborated. In order to modifying the existing framework well enough to explain how mini-box service retailers balance the total number of stores between market penetration and market expansion, we hereby introduce two concepts into the framework: the degree of outlet concentration and the market selection method.

The degree of outlet concentration indicates how firms focus on a specific market. It could also be a suitable index showing the extent to which firms allocate their outlets across geographic regions. Herfindahl-Hirschman Index (HHI) is used as an index to quantify the degree of concentration. If a firm opened all outlets in a single geographic market, HHI is the highest, 10000. The value decreases with an increase in the number of geographic market where a firm has at least one outlet, and increases with increasing inequality of share of stores between geographic markets. A trade area of mini-box service retailers' each outlet tends to be very small, so the unit of geographic markets should be as small as possible when analyzing the degree of concentration.

In addition to the degree of outlet concentration, we have taken into the existing framework another important concept, that is, the market selection method, or how to choose the new geographic market. After forming an area dominant in a certain area, new geographic markets should be selected by firms wisely to secure company-wide profitability to finance developing more stores and growing the brands nationally. Actually, in practical fields, the most commonly asked questions are "Where is the next market?" or "Is this market correct for us as a next step?" Facing these questions, it seems to be helpful to take some knowledge in international marketing literature into account. According to Albaum et al (1994), there are two methods of market selection at the country level: Proactive Approach and Reactive Approach.

Proactive Approach is marketing-oriented. Firms are active in initiating the selection of new geographic markets. This approach is systematic and formalized, and it tries to select markets where sales potential is considered to 


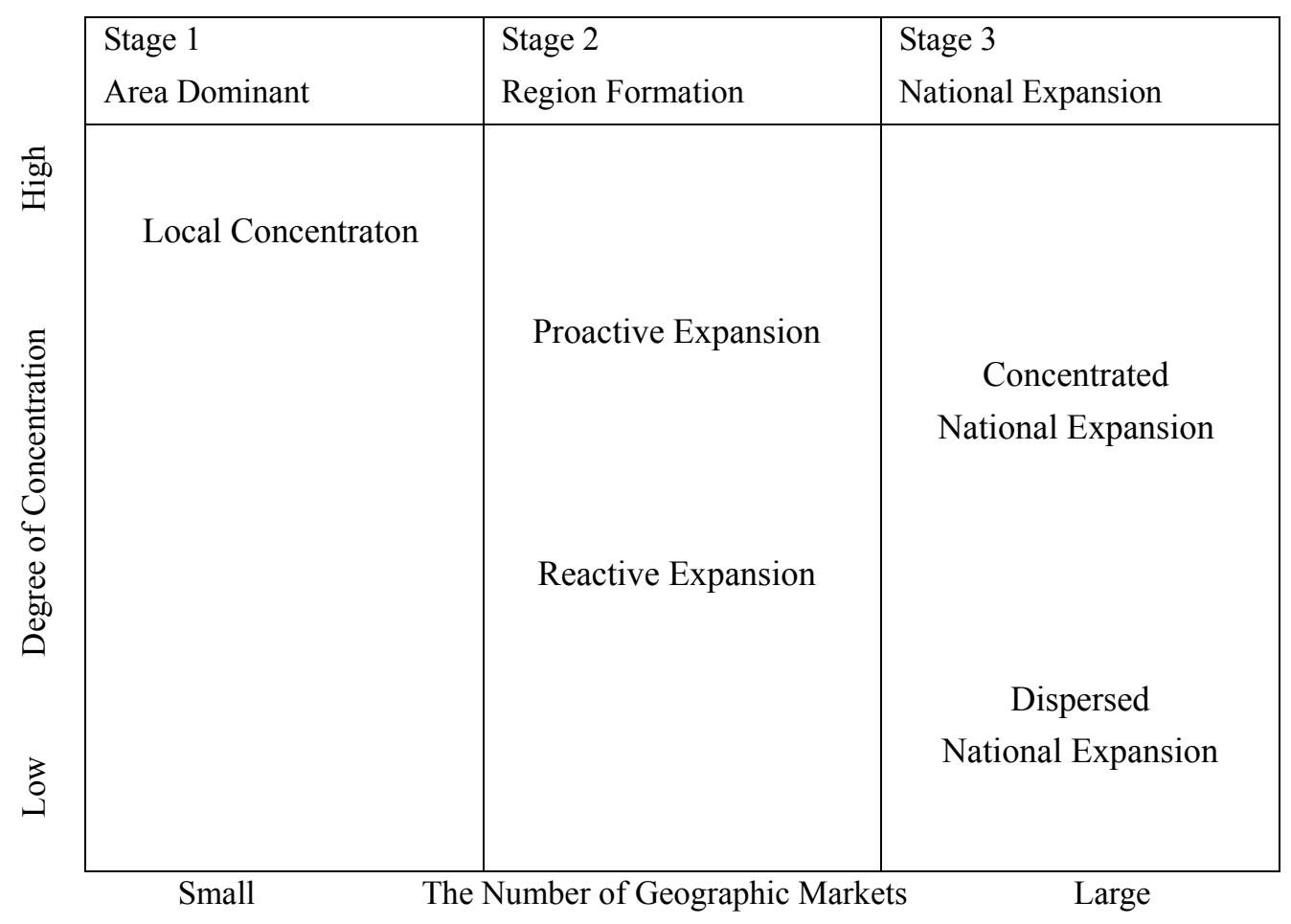

Figure 2. Market expansion strategies for mini-box service retailers

be sufficient. In contrast to Proactive Approach, Reactive Approach selects markets in a piecemeal and in an unplanned manner. A characteristic situation of Reactive Approach is when firms act passively in selecting new geographic markets and open stores because there are development opportunities by chance. By taking these qualitative distinctions into account, the expansion strategies of mini-box service retailers were classified into five categories (Figure 2).

Local Concentration is the starting point. It is a strategy directed at developing as many outlets as possible to get a high coverage rate in an existing market. Outlets are developed in a very limited number of areas intensively and degree of store concentration is the highest. As a result, it can be expected that the location convenience for customers improves and then the customers' usage frequency increases. However, market becomes saturated as a result of continuous development of outlets in a certain area, which leads to sales cannibalization between outlets. Furthermore, it is hard for the firms to expect both economies of scale and corporate profit growth if they focus on only one area. These factors will force firms to expand their market by going to new geographic markets aggressively. In this stage, the way of expansion is divided into two: Proactive Expansion and Reactive Expansion.

Proactive Expansion is to direct at both selecting and focusing on the high-potential market actively. Degree of store concentration ranks second. Reactive Expansion is to open stores wherever if there are development opportunities. Firms with Reactive Expansion often expand geographic markets randomly so that degree of store concentration tends to be low. Firms expanding this way lack a location strategy.

National Expansion is the final stage of market expansion in the domestic market and is also divided into two types: Concentrated National Expansion and Dispersed National Expansion. Concentrated National Expansion is to keep degree of store concentration high for markets where the firms initially dominated. Firms running a highly centralized operation even after they expand their store network to national level are considered to take this method. Dispersed National Expansion is to disperse total outlets nationally with lower degree of store concentration. Firms running decentralized operation or firms expanding nationally by Reactive Expansion are considered to take this method.

As stated above, market expansion strategies of mini-box service retailers in domestic market were classified into five, by introducing the degree of outlet concentration and the market selection method into the existing framework. 


\subsection{Hypothesis}

Secondary effects to be brought from concentrating additional outlets in a specific region are mentioned in the retailing and service literatures. It has been shown that concentrating additional outlets in a specific region brings synergy effects from several sources. More outlets may have greater promotional impact on customers. Customers may easily identify the firm with more outlets as a leading brand company. An image of reliability and consistency will also be given to customers. Economies of scale may also arise with advertising by supporting a number of branches in the region as well as by exploiting a standardization achievement. Regarding the customer base, more outlets in a region means customers can remain loyal due to locational convenience. They are hardly forced to try competitor's offerings because the competitor has lost the opportunity to have outlets in convenient locations in the same region. These factors mean that adding a new branch may increase average sales of all the outlets of the firm in the region. Concentrating branches within a specific region also brings significant economies of scale in marketing, distribution, and administrative overheads. For example, adding another outlet to an area where the company already advertises heavily is unlikely to lead to a proportionate rise in advertising costs, while opening new outlet in a region where the firm has no previous presence will require disproportionately high advertising costs with no spillover advantages for neighboring outlets. Distribution, inventory and administrative expenses are usually lower for a more concentrated network of outlets due to better use of the existing logistical network. A strong correlation between a firm's regional market share and profitability was identified (Furhan 1972). Comparing gaining toehold positions in a larger number of city market areas with devoting resources to building a leading position in one region at a time, it appears that the latter strategy usually pays off better (Doyle and Corstjens 1983).

Following these existing service marketing and retailing literatures, local concentration strategy could lead to the highest profitability due to dominant effects. Concentrating stores in a certain market also develops sales momentum, maximizing the chain's infrastructure, and deters competitors.

However, it is hard for firms to expect both economies of scale and corporate profit growth if they stay in only one area. Moreover, the market will become saturated at some point, and new store development will find it difficult to gain a foothold. Increasing the number of outlets in one region will lead to sales cannibalization, which will result average outlet sales decline. The possibility that competitors are recognized as the top brand in other markets will rise if a firm is late to go into new markets. Though these factors encourage firms to expand their store networks after forming area dominant despite the restriction of logistics costs, firms lack knowledge regarding how they should expand their store networks until covering market nationally, as well as how corporate performance will be affected by the store expansion.

We try to formulate hypotheses regarding the relationship between types of market expansion strategies and corporate performance. Profitability is taken as an indicator of the economic performances, which is measured by operating income to sales ratio of the firm. Four hypotheses are put forward by comparing profitability of firms adopting local concentration strategy and that of firms adopting other four strategies respectively.

The geographic position of stores is considered to influence corporate performance. In this study we focus on profitability as an indicator of corporate performance. Profitability can be broken down into revenue and cost. Firms can expect revenue in a market where there is sufficient demand in a country. So, revenue is expected to be higher in firms operating in markets with high sales potential than in firms operating with low sales potential. However, the costs of delivering goods and services, administration, transportation and financing are related to distances from headquarters, warehouses, and locations of other outlets. If firms expand their market to the wider area, the dominant effects are expected to decrease leading to lower profitability (Jones and Simmons 1990). Opening stores by selecting the locations in new market means it would have very dispersed network with a high cost structure. The geographic distance between stores is important. If firms run a highly centralized operation keeping profitability high, all outlets should be located within the area where is accessible by supervisors or delivery trucks from the head office. Therefore if mini-box service retailers would like to expand their market, they need to form new dominant area by adding new outlets in a newly developed area after expansion. If they put an effort too much on market expansion and fail to increase the market share in new markets where they have developed at least one outlet, profitability is expected to decrease.

If mini-box service retailers adopt Proactive Expansion strategy, that is, if they select high-potential markets aggressively and concentrate the number of store there through additional store development, sales increase is expected by the synergy effects between outlets and cost performance is expected to improve on some activities regarding logistics, store management, advertising and so on. In high-potential markets, competitions for sophisticated locations and part-time workers are tight, leading to soar of the rent fee and personnel expense. 
Though there are such potential downsides of Proactive Expansion, we hypothesized that they have an overall positive effect on performance of firms. Thus we formed the hypothesis 1 as follows.

Hypothesis 1: Profitability is higher in firms adopting Proactive Expansion strategy than in firms adopting Local Concentration strategy.

If mini-box service retailers adopt Reactive Expansion strategy, that is, if they select new markets without taking market potential into account or if they expand to high-potential market because there were opportunities to open outlets by chance and fail to develop outlets additionally, they would have very dispersed network with a high cost structure. For example, they are expected to be less motivated to build distribution centers because they do not have enough number of stores to cover the cost of maintaining distribution centers, leading to high logistics costs. Furthermore, if firms select high-potential markets aggressively but fail to concentrate the number of store there through additional store development, neither sales increase by the synergy effects between outlets nor improvement of cost performance on some activities regarding logistics, store management, advertising and so on, are expected. Competitors may also have chances to develop more outlets in the market, which means firms lose opportunities to raise their shares in the same market. Thus the hypothesis 2 is formed as follows.

Hypothesis2: Profitability is lower in firms adopting Reactive Expansion strategy than in firms adopting Local Concentration strategy.

On the stage where firms try to expand their market nationally, if they scatter outlets in various places where are away from existing markets, logistics cost will be skyrocketed. If firms cover the domestic market nationally by running a highly centralized operation, they would have a very high cost structure. If mini-box service retailers adopt concentrated national expansion strategy, that is, if they open outlets nationally with keeping the degree of outlet concentration relatively high, profitability is expected to be lower because sales increase in relatively new markets is not expected by the synergy effects between outlets, and because logistics costs will be higher due to the longer distance between outlets. Cost performances on store management, advertising and so on are expected to be worse. Thus the hypothesis 3 is formed as follows.

Hypothesis3: Profitability is lower in firms adopting Concentrated National Expansion strategy than in firms adopting Local Concentration strategy.

On the contrary to adopting Concentrated National Expansion strategy, if they open outlets nationally with decreasing the degree of concentration of store to lower level, profitability is expected to be high because sales increase in relatively new markets is expected by the synergy effects between outlets, and because cost performance is expected to improve on some activities regarding store management, advertising and so on. Logistics costs will also be lower if they could develop individual logistics system in each area where firms dominate. Thus the hypothesis 4 is formed as follows.

Hypothesis4: Profitability is higher in firms adopting Dispersed National Expansion strategy than in firms adopting Local Concentration strategy.

\section{Case Study for Japanese Food Service Industry}

\subsection{Classification of Firms by Strategy}

Out of total 81 food service companies listing stock in Japan, some firms are omitted from subjects of this research: firms operating as mega franchisees of other listed companies e.g., Kannanmaru / Fujita Corporation, firms spreading their business to more to non-food service sector e.g., Daskin / Watami / Totenko, firms that have some special rules in preparing for their financial statements such as McDonald / Kazokutei, and subsidiaries of another listed food service company e.g., Atom / Cocos / Sunday's Sun. Finally 52 Japanese listed companies focusing exclusively on food service are chosen as subjects in this research.

Prefecture is used as a unit of geographic market in considering market expansion strategy. There are 47 prefectures in Japan. Tokyo is the largest prefecture in terms of population and Kanagawa, Chiba, Saitama, Osaka, Aichi (Nagoya), Fukuoka, Miyagi (Sendai), Hokkaido (Sapporo) are major prefectures where more than a million people reside.

For classifying companies by strategy, we prepared data as follows. At first their store number by prefecture are counted by studying firms' web sites and annual reports. Secondly, both shares of store counts in each prefecture and the number of prefecture where firms have opened at least one store are calculated. Then the degree of concentration is calculated by using HHI. This index is calculated as the sum of squares of percentage of the number of outlets in each prefecture. Maximum concentration occurs when all the outlets is developed to only one prefecture and minimum concentration exists when outlets are equally allocated over all prefectures. 
10 firms are categorized into Local Concentration, which limit the number of prefectures where they operate at least one outlet by ten. Prefectures are connected geographically around a prefecture where they initially developed their outlet.13 firms are in Proactive Expansion, which select up to three major markets and open outlets intensively there. HHI is less than that of Local Concentration but more than 1000. 8 firms are classified into Concentrated National Expansion, which has gone into all major cities throughout Japan, and store concentration in a certain market is still high. HHI should be more than 1000. 15 firms are classified into Dispersed National Expansion, which has gone into all major cities throughout Japan and store concentration in a certain market is low. They disperse stores by opening more additional outlets in each major market and HHI is under 1000. Finally, 7 firms are classified into Reactive Expansion, which are not categorized to other four types.

The details of sample firms by strategy are shown in Table 1. Table 2 shows average of HHI, the number of developed prefectures, operating income to sales ratio, store counts and cost of goods sold by the type of strategy. Figure 3 shows the relationship among HHI and the number of prefectures.

\subsection{Analysis}

A 5-year average (2005-2010) operating income to sales ratio defined as operating income divided by sales was chosen as a profitability measure. First, operating income to sales ratio for each of the years 2005-2010 by studying firms' annual report, and then an average operating income to sales ratio across the years was determined.

To determine the relationship between the profitabitlity and the type of expansion strategies, the following regression was run:

$$
\text { Profitability }=a+b \operatorname{Cogs}+c P E+d R E+e N E H+f N E L
$$

Cogs is the cost of good sold to sales ratio. PE, RE, NEH and NEL are dummy variables representing Proactive Expansion, Reactive Expansion, Concentrated National Expansion and Dispersed National Expansion, respectively. Local concentration is dealt as the reference group.

Then, by removing cost of goods sold from (1), the following regression was run:

$$
\text { Profitability }=a+b P E+c R E+d N E H+e N E L
$$

Results of two regressional analyses are shown in Table 3.

As indicated in Table 3, coeffcients of PE and LHI are positive as well as significant at least $5 \%$ level in regression (1), which means that firms adopting PE and LHI strategies are more profitable than those adopting LC strategy. Furthermore, even if cost of goods sold is omitted from independent valuables, sign of coefficients of both PE and LHI are positive as expected, and they are also statistically meaningful in regression (2). That means even if we take the differences of cost of goods sold into account, profitability of both PE and LHI tend to be higher than that of LC. Therefore both hypothesis 1 and hypothesis 4 are supported. Regarding Reactive Expansion, though sign is negative as expected, coefficient itself is not statistically meaningful. For Concentrated National Expansion strategy, sign is positive against our expectation and coefficient itself is not statistically significant. Therefore both hypothesis 2 and hypothesis 3 were not supported. 
Table 1. Sample firms by strategy

\begin{tabular}{|c|c|c|c|c|c|c|}
\hline $\begin{array}{l}\text { Type } \\
\text { Of } \\
\text { Strategy }\end{array}$ & Company & $\begin{array}{l}\text { Store } \\
\text { Count }\end{array}$ & $\begin{array}{l}\text { The } \\
\text { Number of } \\
\text { Prefectures } \\
\text { Entered }\end{array}$ & HHI & $\begin{array}{l}\text { Operating } \\
\text { Income to } \\
\text { Slaes Ratio } \\
(\%)\end{array}$ & $\begin{array}{l}\text { Cost of } \\
\text { Goods } \\
\text { Sold } \\
(\%) \\
\end{array}$ \\
\hline Local & Anrakutei Co., Ltd & 253 & 9 & 2415 & 2.4 & 33.1 \\
\hline \multirow{9}{*}{ Concentration } & Choshimaru Inc & 68 & 4 & 3166 & 5.8 & 42.7 \\
\hline & Flying Garden Co.,Ltd & 67 & 5 & 2225 & 3.5 & 30.9 \\
\hline & Friendly Corporation & 108 & 6 & 4966 & -0.8 & 31.2 \\
\hline & Ginza Renoir Co., Ltd & 107 & 4 & 8276 & 1.9 & 11.6 \\
\hline & Hiday Co., Ltd & 252 & 4 & 3960 & 9.4 & 27.3 \\
\hline & Karla Co., Ltd. & 93 & 9 & 1856 & 2.2 & 32.1 \\
\hline & Life Foods Co., Ltd & 118 & 11 & 2598 & 3.2 & 31.2 \\
\hline & Tokyo Ichiban Foods Co., Ltd & 48 & 4 & 5356 & 5.7 & 30.6 \\
\hline & Towa Food Service Co., Ltd & 116 & 4 & 4117 & 4.9 & 26.4 \\
\hline Proactive & Akindo Sushiro Co., Ltd & 180 & 19 & 1385 & 3.2 & 51.3 \\
\hline \multirow[t]{11}{*}{ Expansion } & Amiyaki Tei Co., Ltd & 138 & 6 & 5346 & 11.1 & 38.3 \\
\hline & Arcland Service Co., Ltd & 87 & 8 & 1901 & 10.2 & 44.7 \\
\hline & Bronco Billy Co., Ltd & 65 & 7 & 3127 & 17.5 & 29.3 \\
\hline & Hub Co., Ltd & 61 & 8 & 4700 & 3.9 & 27.4 \\
\hline & Ichirokudo Co., Ltd & 84 & 5 & 7812 & 8.8 & 25.1 \\
\hline & Kichiri \& Co., LTd & 48 & 6 & 4557 & 2.0 & 30.1 \\
\hline & Kisoji Co., Ltd & 186 & 16 & 1959 & 2.2 & 31 \\
\hline & Ohsho Food Service Corporation & 543 & 28 & 1188 & 12.1 & 30.4 \\
\hline & Sanko Marketing Foods Co., Ltd & 129 & 6 & 5326 & 10.2 & 26.1 \\
\hline & Sato Restaurant Systems Co., Ltd & 206 & 16 & 1346 & 2.4 & 29.3 \\
\hline & Y.S.Food Co., Ltd & 47 & 15 & 1870 & 6.5 & 33.2 \\
\hline Reactive & Hachi-ban Co., Ltd. & 166 & 12 & 2461 & 3.5 & 48.5 \\
\hline \multirow{6}{*}{ Expansion } & JB Brain Co., Ltd. & 67 & 11 & 3776 & 2.9 & 28.4 \\
\hline & Korakuen Corporation & 422 & 29 & 609 & 4.9 & 28.1 \\
\hline & Maruchiyo Yamaokaya Corporation & 111 & 16 & 667 & 3.7 & 26.6 \\
\hline & Ringer Hut Co.,Ltd & 557 & 29 & 1018 & 1.7 & 27.4 \\
\hline & Sagami Chain Co., Ltd & 258 & 15 & 2854 & 0.9 & 30.1 \\
\hline & Sakai Co., Ltd & 144 & 27 & 664 & 2.3 & 37.1 \\
\hline Concentrated & Daisyo Corporation & 940 & 44 & 2108 & 2.4 & 36.1 \\
\hline National & KANMONKAI. Co. ,Ltd & 85 & 10 & 3345 & 3.8 & 34.2 \\
\hline \multirow[t]{6}{*}{ Expansion } & Marche Corporation & 632 & 19 & 1236 & 4.1 & 37.8 \\
\hline & Matsuya Foods Co., Ltd & 741 & 28 & 1945 & 6.4 & 31.7 \\
\hline & Ootoya Co., Ltd. & 213 & 38 & 1632 & 3.1 & 36.1 \\
\hline & Pepper Food Service Co., Ltd & 189 & 37 & 1126 & 3.2 & 53.1 \\
\hline & Starbucks Coffee Japan., Ltd & 831 & 42 & 1173 & 5.9 & 28.7 \\
\hline & The Monogatari Corporation & 68 & 20 & 1244 & 7.6 & 24.7 \\
\hline Dispersed & B-R 31 Ice Cream Co., Ltd. & 1042 & 47 & 421 & 14.2 & 38.7 \\
\hline National & Corowide Co., Ltd & 913 & 25 & 792 & 3.3 & 30.5 \\
\hline \multirow[t]{13}{*}{ Expansion } & Create Restaurants Group & 365 & 32 & 660 & 4.8 & 27.9 \\
\hline & Genki Sushi Co., Ltd & 191 & 18 & 978 & 2.1 & 40.8 \\
\hline & Ichibanya Co., Ltd. & 1181 & 47 & 611 & 9.7 & 46.6 \\
\hline & Joyful Co., Ltd & 709 & 37 & 684 & 3.4 & 35.7 \\
\hline & Kentucky Fried Chicken Japan Ltd & 1509 & 47 & 549 & 3.2 & 49.5 \\
\hline & Kura Corporation & 245 & 30 & 868 & 5.7 & 49.2 \\
\hline & Moss Food Services, Inc & 1302 & 47 & 459 & 2.9 & 55.7 \\
\hline & Saintmarc Holdings Co., Ltd & 583 & 41 & 805 & 19.6 & 25.5 \\
\hline & Saizeriya Co., Ltd & 797 & 25 & 988 & 9.3 & 35.5 \\
\hline & Toridoll Corporation & 365 & 40 & 576 & 9.4 & 27.5 \\
\hline & WDI Corporation & 151 & 34 & 758 & 2.1 & 24.7 \\
\hline & Yoshinoya Holdings & 1167 & 47 & 705 & 5.0 & 38.2 \\
\hline & Zensho Co., Ltd & 1297 & 47 & 479 & 4.8 & 38.4 \\
\hline
\end{tabular}


Table 2. Characteristics by strategies

\begin{tabular}{|c|c|c|c|c|c|c|}
\hline Type of Strategy & Firms & $\begin{array}{l}\text { The Degree } \\
\text { of Concentration }\end{array}$ & $\begin{array}{l}\text { The Number } \\
\text { Of Prefectures } \\
\text { Entered }\end{array}$ & $\begin{array}{l}\text { Operating } \\
\text { Income to } \\
\text { Sales Ratio }\end{array}$ & $\begin{array}{l}\text { Store } \\
\text { Counts }\end{array}$ & $\begin{array}{l}\text { Cost of } \\
\text { Goods Sold }\end{array}$ \\
\hline Local Concentration & 10 & 3894 & 6.0 & 3.8 & 123.0 & 29.7 \\
\hline Proactive Expansion & 12 & 3399 & 11.4 & 6.9 & 145.5 & 32.8 \\
\hline Reactive Expansion & 7 & 1721 & 19.9 & 2.9 & 246.4 & 32.3 \\
\hline $\begin{array}{l}\text { Concentrated } \\
\text { National Expansion }\end{array}$ & 8 & 1726 & 29.8 & 4.6 & 462.4 & 35.3 \\
\hline $\begin{array}{l}\text { Dispersed National } \\
\text { Expansion }\end{array}$ & 15 & 689 & 38.0 & 6.6 & 787.8 & 37.6 \\
\hline
\end{tabular}

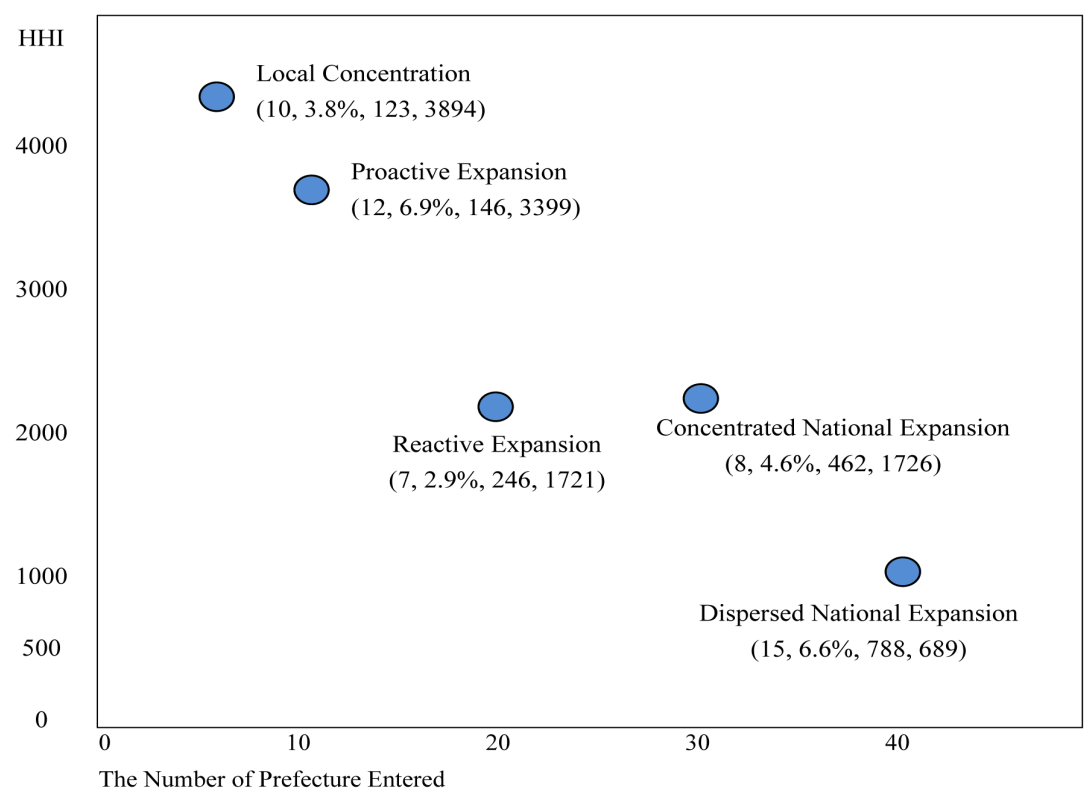

Figure 3. Market expansion strategies of Japanese food service firms

*Number in parenthesis shows the number of firms, the average operating income to sales ratio, the average store count, and the average $\mathrm{HHI}$ in order.

Table 3. Results of regressional analysis

\begin{tabular}{lllll}
\hline \multirow{2}{*}{ Regresion } & $(1)$ & & $(2)$ & \\
& Coef. & t value & Coef. & t value \\
\hline Cogs & -0.0793 & -1.180 & - & - \\
PE & $3.9673^{* *}$ & 2.350 & $3.7051^{* *}$ & 2.21 \\
RE & -0.7659 & -0.400 & -0.9725 & -0.50 \\
NEH & 1.1879 & 0.630 & 0.7446 & 0.40 \\
NEL & $3.4379^{* *}$ & 2.050 & $2.8101^{*}$ & 1.76 \\
cons & $6.1795^{* *}$ & 2.630 & $3.8233^{* * *}$ & 3.09 \\
R-squared & 0.1991 & & 0.1749 & \\
Adj-R-squared & 0.1120 & & 0.1047 & \\
N & 52 & & 52 & \\
$* \mathrm{p}<0.1, * * \mathrm{p}<0.05, * * * \mathrm{p}<0.01^{* *}$ & & &
\end{tabular}




\section{Conclusions and Managerial Implication}

\subsection{Conclusions}

By introducing the degree of concentration and the market selection method into existing retail growth strategy's framework, market expansion strategies of mini-box retailers were categorized into five types: Local Concentration, Proactive Expansion, Reactive Expansion, Concentrated National Expansion, and Dispersed National Expansion. Interesting point is that the most profitable strategy is not Local Concentration for building dominance but Proactive Expansion.

As mentioned in hypothesis, competitions for sophisticated locations and part-time workrers are tight in high-potential markets, which will likely to result increase in the rent fee and labor cost. Though there are such potential downsides with Proactive Expansion, it seems that high sales potential in large markets can offset the high costs in Japanese food service market.

After forming an area dominant by adopting Local Concentration strategy, it is a profitable way to expand market by selecting high-potential markets proactively and penetrating them. Firms should go into large cities aggressively at relatively early stage with decreasing the degree of outlet concentration gradually. Dispersed National Expansion is also more profitable than Local Concentration, which means that at the matured stage it is necessary for being profitable as well as for being established as a national brand to scatter outlets nationally with making the degree of concentration lower. How firms select new geographic markets and whether firms can open more outlets additionally in new geographic markets after entering seem to be the key points to make their brand national and profitable. Concentrated National Expansion which scatters outlets nationally and keeps the share of stores high in small number of prefecture is more profitable, though coefficient was not statistically meaningful. The least profitable strategy is Reactive Expansion in the growing stage. If firms expand market with opening their stores that lie scattered in various places before they form strong dominance in a certain area, their profitability tends to be low. Some reasons can be considered why the profitability of Reactive Expansion is the lowest. When firms go to the local city, potential demand is considered to be low and there may be locally-dominant competitors especially in service field including food service due to its simultaneous production and consumption nature. That means firms are hardly possible to open more outlets in the area, leaving one outlet isolated and making cost performances for logistics and store management extremely inefficient. Even though firms go to a large city, it is hard for them to acquire enough sales to offset soaring costs for rent and labor if they fail to increase market share by adding outlets in the area. During market expansion, profitability is influenced by both the degree of outlet concentration and the market selection method at the prefectural level.

\subsection{Managerial Implication}

Mini-box service retailers have to consider the number and the quality of market where they wish to expand as well as the degree of store concentration depending on their growth stage to succeed in becoming profitable national brands. In the stage for firms to establish an area dominant, the question is where they should dominate. Japanese major cities have characteristics that rail network is highly developed and people tend to be densely populated. Locations facing with terminal station and densely populated areas have commercially high potential, where retailers such as department stores and GMS locate their main stores to increase both sales and market presence. Mini-box service retailers tend to rely on the power of attractive location for attracting their customers, and many firms try to expand their store network in major cities. Though sample size is too small to conduct statistical analysis regarding the mean differences, profitability of firms dominating in rural area at their initial stage tend to be lower than that of firms dominating in major cities, especially in Tokyo.

Just after forming an area dominant by adopting Local Concentration strategy, the profitability largely depends on both how they choose new markets and how they allocate the number of new outlets among the markets. In the stage for firms to form regions that is larger than areas in terms of size, profitability is expected to be higher if they select high-potential markets and concentrate new stores there. Regions should be composed of several dominant areas. In this stage firms have to keep the degree of concentration relatively high, though it is lower than the previous stage. For that purpose, firms should wisely choose markets with high possibility to open more outlets. Area strategy and enough cash for adding stores regularly are also necessary. On the contrary, profitability is likely or easy to decrease if firms choose markets without thought about after entry that result the stores to be scattered randomly in wider area. This situation gives serious effect to profitability of food service firms. In many cases food service firms rely on local suppliers with foodstuffs supply because many of them deal with stuffs that freshness is considered to be important by customers. Much of the stuffs is perishable and requires frequent replenishments. Therefore a few stores in a certain area make it hard for firms to decrease cost 
of goods sold, leading to lower profitability.

In the stage for firms to expand nationally, they have to change a principle for market expansion dramatically. That is, firms should decrease concentration of new store to achieve higher profitability. If they continue to keep concentration of new store high in this stage, outlets are scattered to far distance from their headquarters nationally, making their logistics costs rise remarkably. To prevent that kind of situation, firms should forget adding more outlets in area where they dominated at their initial stage. Firms should cover much wider area by locating a large number of outlets. By doing so, firms may be able to use central kitchens or distribution centers effectively. Otherwise, vehicle utilization is maximized, leading to lower profitability.

As a conclusion, it could be suggested how mini-box service retailers should expand their market from locally to nationally in the domestic market. The profitable way of market expansion in the domestic market seems to be as follows; at initial stage, Local Concentration strategy should be adopted. At growing stage, Proactive Expansion strategy should be adopted, after which expansion to surrounding middle or small-sized cities should be conducted. Finally at matured stage, stores should be spread nationally with decreasing store concentration ratio to lower level. If firms suffer from low profitability by expanding reactively, two ways are possible for recovery. One way is to change their expansion strategy to Proactive Expansion by relocating outlets located and isolated in a small city to major cities where more outlets are required to increase firms' market share. Another way is to open more and more outlets aggressively enough to cover the markets nationally, making some dominant areas in major cities. If firms suffer from low profitability by adopting Concentrated National Expansion strategy, it would be valuable to change their expansion strategy to Dispersed National Expansion by decreasing the degree of concentrations of stores.

Making mistakes in adopting suitable market expansion strategy depending on firms' growth stage could lead to negative corporate performances. It is hard to expect that a new store's sales keep increasing or remain stable without adding more outlets in the same area. If firms fail to penetrate the market with additional stores, their corporate profitability would possibly be damaged because they hardly keep existing store's sales as they expected before opening, and also because logistics costs increase, resulting in stagnant corporate growth or in the worse case, business itself to shrink. In Japanese food service industry, many firms declare their target, e.g., to develop 500 or more outlets in Japan within five years. However, considering that there are a lot of cases firms cannot meet the target, suitable market expansion strategy should be adopted carefully, especially at their launch stage. Random or reckless market expansion should be avoided.

\section{Agenda for the Future Research}

Though we only have focused on market expansion in the framework explaining retail growth strategy this time, new classification of market expansion strategy will be required by introducing store format development and furthermore, store brand development to enrich this study. Regarding services that consumers seek variety or services that locational convenience is considered to be a critical factor for customers in choosing stores, in many cases, it is hard for firms to cover a certain geographic market with only one format or one store brand. Therefore, some firms try to occupy sophisticated locations in the same geographic market by developing different formats or store brands, which will also have an effect to deter competitors from developing their new outlets. Considering these facts, market expansion strategy for mini-box service retailers should be classified by taking the aspect of store format or store brand development into account.

Also, as we mentioned in the introduction, there are many kinds of mini-box service retailers other than food service. The same framework should be applied to non-food service field in Japan in future researches, which might be helpful to identify industry-specific factors. If the same framework should be applied to food service industry in countries outside of Japan, it could also be expected to identify country-specific factors.

Though prefecture is used as a unit of geographic market in this research, other geographic units are also available. Prefecture is divided into smaller municipalities, which could also be a unit of geographic market. If it is considered that trade areas for mini-box service retailers tend to vary by firms, location type e.g., urban or suburbs should also be considered. Finally, other corporate performance data e.g., ROI, ROE, should be analyzed in the same framework. By doing so, it would be possible to valuate market expansion strategy of firms from various angles. These attempts would be valuable for mini-box service retailers to grow in domestic market in an effective way.

\section{References}

Albaum, G., Strandskov J., Duerr, E., \& Dowd, L. (1994). International Marketing and Export Management. Addison-Wesley Publishing Company. 
Ansoff, I. (1965). Corporate Strategy. McGraw-Hill.

Bateson, J. E. G., \& Hoffman, K. D. (1999). Managing Services Marketing. The Dryden Press.

Bucklin, R. E., Siddarth S., \& Silva-Risso, J. M. (2008). Distribution Intensity and New Car Choice. Journal of Marketing Research, 45(4), 473-486. http://dx.doi.org/10.1509/jmkr.45.4.473

Buhner, R. (1987). Assessing International Diversification of West German Corporations. Strategic Management Journal, 8, 25-37. http://dx.doi.org/10.1002/smj.4250080104

Carman, J. M., \& Langeard, E. (1980). Growth Strategies for Service Firms. Strategic Management Journal, 1(1), 7-22. http://dx.doi.org/10.1002/smj.4250010103

Doyle, P., \& Corstjens, M. (1983). Optimal Growth Strategies for Service Organizations. Journal of Business, 56(3), 389-405. http://dx.doi.org/10.1086/296207

Elango, B. (2000). An Exploratory Study into the Linkages between Corporate Resources and the Extent and From of Internationalization. American Business Review, 18, 12-26.

Furhan, W. E. (1972). Pyrrhic Victories in Fights for Market Shares. Harvard Business Review, 70(5), 100-107.

Gohshal. S. (1987). Global Strategy: An Organizing Framework. Strategic Management Journal, 8, 425-440. http://dx.doi.org/10.1002/smj.4250080503

Hollensen, S. (2004). Global Marketing. Prentice Hall Publishing.

Jennet, J. P., \& Hennessey, H. D. (2001). Global Marketng Strategies. Houghton Mifflin Company.

Johnson, R. (1996). Achieving Focus in Service Organizations. The Service Industries Journal, 16, January, 10-20. http://dx.doi.org/10.1080/02642069600000002

Jones, K., \& Simmons, J. (1990). The Retail Environment. Routledge.

Kasper, H., Helsdingen, P. V., \& Gabbott, M. (2006). Service Marketing Management: A Strategic Perspective. John Wiley \& Sons.

Knoben, J., Oerlemans, L. A. G., \& Rutten, R. P. J. H. (2008). The Effects of Spatial Mobility on the $\begin{array}{llll}\text { Performance of Firms. Economic } & \text { Geography, }\end{array}$ http://dx.doi.org/10.1111/j.1944-8287.2008.tb00402.x

Kogut, B. (1985a). Designing Global Strategies: Comparative and Competitive Added Value Chains. Sloan Management Review, 26(4), 15-28.

Kogut, B. (1985b). Designing Global Strategies: Profiting from Operational Flexibility. Sloan Management Review, 27(1), 27-38.

Laulajainen, R., \& Stafford, H. A. (1987). Corporate Geography-Business Location Principles and Cases. Kluwer Academic Publishers.

Levy, M., \& Weitz, B. A. (2004). Retailing Management. McGraw Hill.

Lovelock, C., \& Wright, L. (1999). Principles of Service Marketing and Management. Upper Saddle River, NJ: Prentice Hall.

Montgomery, D. B., \& Urban, G. L. (1969). Management Science in Marketing. Enlewood Cliffs, N. J.: Prentice-Hall.

Palmer, A., \& Cole, C. (1995). Services Marketing: Principle and Practice. Prentice-Hall, Inc.

Riddle, D. L. (1986). Service Led Growth. Praeger Publishing.

Simmons, J. W., \& Speck, B. (1988). The Spatial Imprint of Business Strategy. University of Toronto, Department of Geography, Discussion Paper, No. 35.

Tobla, A. H. (2011). The Impact of Distribution Intensity on Brand Preference and Brand Loyalty. International Journal of Marketing Studies, 3(3), 56-66. http://dx.doi.org/10.5539/ijms.v3n3p56 